\title{
Inhalation Vapor, Capsule Dosage Form
}

National Cancer Institute

\section{Source}

National Cancer Institute. Inhalation Vapor, Capsule Dosage Form. NCI Thesaurus. Code C149582.

Solid preparation consisting of a capsule formulation intended for generation of vapor to be inhaled to obtain a local effect. The vapor is usually generated by adding the whole capsule or the capsule contents to hot water. 